\title{
A pot line Rectiformer scheme with hybrid-shunt active power filter
}

\author{
Fadhel Abbas Albasri' ${ }^{1}$, Sayed Ali Al-Mawsawi ${ }^{1}$, Mahmood Al-Mahari ${ }^{2}$ \\ ${ }^{1}$ Department of Electrical and Electronics Engineering, University of Bahrain, Isa Tawn Campus, Bahrain \\ ${ }^{2}$ Aluminium Bahrain (ALBA), Manama, Bahrain
}

\begin{tabular}{l}
\hline Article Info \\
\hline Article history: \\
Received Aug 22, \\
Revised Jan 19, 202 \\
Accepted Jan 24, \\
\hline Keywords: \\
Active filters \\
Harmonic filters \\
Power filters \\
Metals industry \\
Power industry \\
Rectifiers
\end{tabular}

\section{Corresponding Author:}

Fadhel Abbas Albasri

Department of Electrical and Electronics Engineering, College of Engineering, University of Bahrain Isa Tawn Campus, P.O. Box: 32038, Bahrain

Email: falbasri@uob.edu.bh

\begin{abstract}
Passive harmonic filters (PHF) are commonly used in conventional potline rectifier transformers (Rectiformer) schemes of aluminum smelters to improve the power quality and reduce harmonic distortions to an acceptable level. However, changes in operating conditions and system configuration affect the performance capability of PHF in attenuating harmonics. In this paper, a Rectiformer scheme with hybrid-shunt active power filter (SAPF) is used instead of PHF and compared with the other commonly applied schemes in aluminum smelter in terms of harmonic attenuation capability. The SAPF potline Rectiformer scheme and other schemes are modeled and simulated using MATLAB/Simulink. A control strategy suitable for potline load behavior is furnished in this paper for SAPF. The simulation results reveal the performance superiority of the proposed SAPF as compared to the conventional and ALBA pot line (PL) 6 schemes.
\end{abstract}

This is an open access article under the CC BY-SA license.

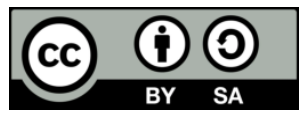

\section{INTRODUCTION}

Aluminum smelter potline rectifier transformers (Rectiformers) scheme consist of four to six units connected in parallel in order to supply the required DC power to the potline. Phase shift technique and passive harmonic filter (PHF) are commonly used with Rectiformers in smelter power network to attenuate harmonics and to support the network with reactive power. Two schemes are generally used for smelter potline Rectiformers. The PHF is either connected directly to the feeding grid or connected to each Rectiformer regulating transformer tertiary winding. Active power filter is still not used with potline Rectiformers due to cost or unavailability of semiconductor devices with the required ratings.

Control of harmonics can be archived mainly by three methods [1]; namely, passive filters, phase multiplication and harmonics compensation or injection (active filters). Passive harmonic filter (PHF) is affected by the change in the power network which will result in retuning and may increase the harmonic distortions [2]. Smelters are always in continuous improvements for enhancing the efficiency and increasing the production. For this reason, many changes in the network is expected to take place. For example, generators may be added to the power network in order to increase the megawatts installed capacity to satisfy the smelter demand. In addition, distribution transformers may be installed to interconnect different substations in order to have flexible and redundant power sources. These changes can alter the source or network impedance and my lead to a deterioration in the PHF performance in attenuating the targeted harmonics. On the other hand, the phase multiplication method is capable to reduce the AC input line current harmonics and DC output voltage ripple. However, due to the conditions that never fulfilled and other 
practical reasons discussed in [3], makes this method not sufficient alone for harmonic elimination. The application of the third method (harmonic compensation) to eliminate the harmonics in a potline Rectiformers system is considered as a modern solution for harmonic distortion problems. In addition, it is not affected by the variation in the supply impedance and hence considered as a major advantage of parallel active filter over passive filter [4].

The first design of harmonic compensators is introduced in 1976 under the name of "active AC power filters" consisting of pulse width modulation (PWM) inverters using power transistors concept. However, the implementation was not possible due to unavailability of the device with the required power at that time [5]. In 1984, a new control strategy based on an instantaneous reactive power compensator (instantaneous $\mathrm{p}-\mathrm{q}$ theory) is introduced for active filter (AF) [6]. Later on, the same control strategy is further developed to provide more adequate compensation characteristic. The most commonly applied control strategies for AF are the instantaneous active and reactive power theory algorithm [7], and the synchronous reference frame method (d-q transformation) [8]. There are other time domain methods, such as high pass and low pass filter method, that have also been reported in literature. However, due to their flaws in extracting the magnitudes and phase angle of the harmonics accurately, these methods were not adopted. A review of the control techniques was presented in [9]. Frequency domain analysis methods has also been used for extracting the reference current for AF by computing the harmonics using discrete fourier transform (DFT) technique [10]-[11]. This approach is robust, noise tolerant and effective to remove the fundamental load current harmonics [12].

Conventional pot line scheme is consisting of six Rectiformers connected in parallel and each is phase shifted in order to achieve 72 pulse system which effectively reduces the harmonic currents at point of common coupling (PCC). In such scheme, the PHF is connected directly to the feeding grid and this is mostly employed to mitigate the harmonic distortions and for reactive power compensation [13]-[16]. The conventional scheme is shown in Figure 1 (a). In this scheme, the harmonics will always flow in the regulating transformer.

There is another alternative scheme, in which the harmonic filter is connected to the regulating transformer tertiary winding of each Rectiformer unit, has also been employed [17]-[20]. The work presented in [17] discussed the most economical method to maintain the voltage THD within $2 \%$ which is achieved by connecting the PHF to the regulating transformer tertiary winding. PHF connected to tertiary winding scheme is also discussed in [18]. Connecting the PHF to the tertiary winding reduces the harmonic effects by creating low impedance path for harmonic to flow and achieves the customer commercial goals by reducing the reactive power demand which will result in an optimized sizing of equipments such as power cables. The new scheme for Aluminum Bahrain (ALBA) pot line 6 (PL6) Rectiformer units is based on PHF connected to the regulating transformer tertiary winding as shown in Figure 1 (b). This configuration is adopted in order to satisfy the IEEE 519 recommended distortion limits. Similar scheme has already been implemented in Ma'aden (Saudi Arabian Mining Company) [19]. A new pot-line Rectiformer scheme is proposed in [20] to reduce the harmonics distortion and compared with the conventional and ALBA PL6 schemes in terms of harmonic elimination capability, operational constrains and cost/space requirements. The PHF presented in [20] is connected to the parallel link of two delta-connected tertiary windings for adjacent Rectiformers in order to reduce the number of the HF filters. The parallel link has effectively reduced the THD in the primary current of the regulating transformer to less than $1 \%$ and reduced the overall distortion level at PCC for various operating conditions. In this paper, a shunt active power filter (SAPF) will be employed instead PHF and its performance will be compared with the conventional and ALBA PL6 schemes in terms of harmonic attenuation capability.

The contribution of this paper is a new Rectiformer scheme with hybrid of PHF and SAPF is proposed to improve the overall harmonic attenuation capability in aluminum potline industrial systems under various operating conditions and contingencies. The proposed scheme combines the advantages of the PHF and SAPF filters in which the PHF is designed to provide the required reactive power compensation and tuned to attenuate the dominating $5^{\text {th }}$ and $11^{\text {th }}$ harmonics, whereas the SAPF is designed to be cost effective and primarily used to enhance the overall Hamonic elimination performance over wide dynamic operating conditions. The proposed hybrid filtering scheme aims to reduce the required rating of the SAPF and thus reducing its cost. A suitable control strategy for the potline load behavior is implemented for the SAPF. The performance of the proposed hybrid scheme is compared with the other commonly applied schemes in aluminum smelter in terms of harmonic attenuation capability. The simulation results reveal the performance superiority of the proposed hybrid PHF-SAPF as compared to the conventional and ALBA PL6 schemes. 


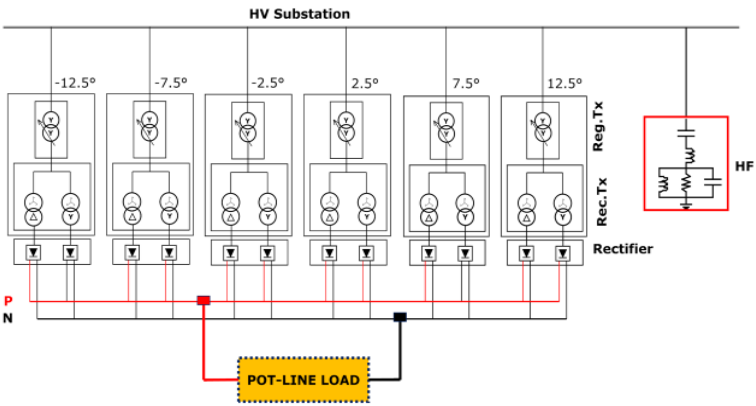

(a)

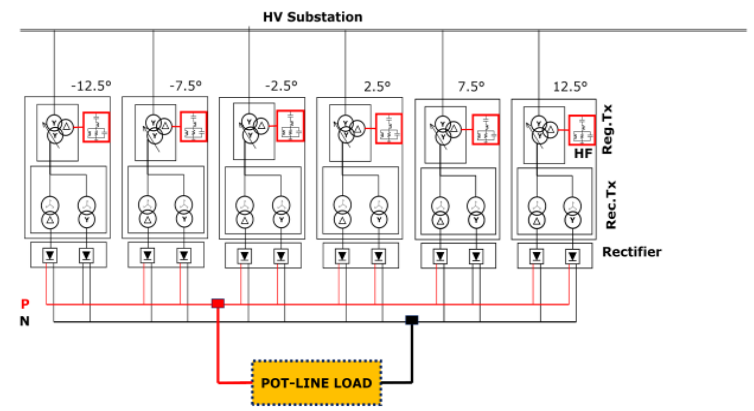

(b)

Figure 1. Aluminum pot line Rectiformers scheme (a) conventional scheme and (b) ALBA PL6 scheme

\section{SHUNT ACTIVE POWER FILTERS (SAPF)}

Active power filters can be classified based on their configuration as shunt or series connected. At present, SAPF are more preferable than series configuration in terms of form and function [6] and it is currently more recognized configuration in the literature. SAPF is connected in parallel to the harmonic source and injects appropriate current harmonics into the AC system by continuously monitoring the load current. The system configuration of the SAPF is shown in Figure 2. The SAPF is connected in parallel with three phase diode rectifier load. The SAPF extract the fundamental current and its phase angle from load current using DFT algorithm and then convert it to time domain. The reference current $\left(\mathrm{I}_{\mathrm{h}}\right)$ is calculated by subtracting the fundamental current $\left(\mathrm{I}_{\mathrm{Lf}}\right)$ from the load current $\left(\mathrm{I}_{\mathrm{L}}\right)$. Finally, the SAPF current $\left(\mathrm{I}_{\mathrm{A}}\right)$ is subtracted from the reference current $\left(\mathrm{I}_{h}\right)$. The result of this subtraction is sent to a hysteresis controller which will generate the switching pattern of the inverter. This switching pattern will force inverter output to follow the harmonics generated by the load [11].

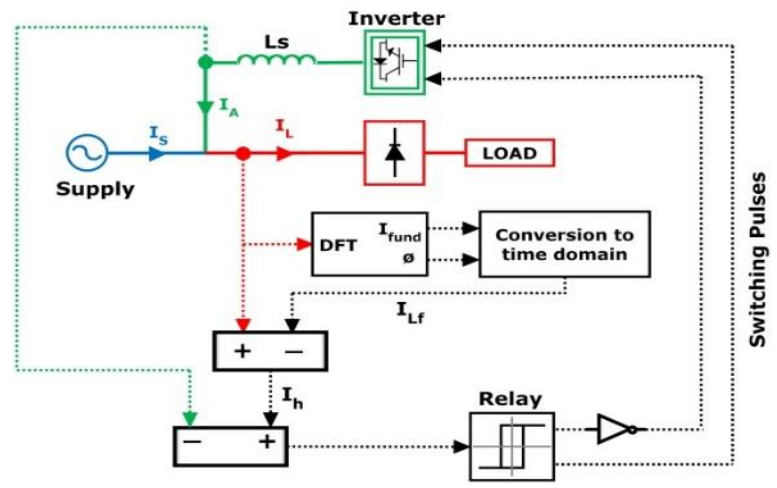

Figure 2. Configuration of the SAPF

At steady state condition, the active filter current (IA) can be found from Figure 2 as:

$$
\begin{aligned}
& \mathrm{I}_{\mathrm{Aa}}=\mathrm{I}_{\mathrm{La}}-\mathrm{I}_{\mathrm{Lfa}}=\mathrm{I}_{\mathrm{ha}} \\
& \mathrm{I}_{\mathrm{Ab}}=\mathrm{I}_{\mathrm{Lb}}-\mathrm{I}_{\mathrm{Lfb}}=\mathrm{I}_{\mathrm{hb}} \\
& \mathrm{I}_{\mathrm{Ac}}=\mathrm{I}_{\mathrm{Lc}}-\mathrm{I}_{\mathrm{Lfc}}=\mathrm{I}_{\mathrm{hc}}
\end{aligned}
$$

Where:

$\mathrm{I}_{\mathrm{A}(\mathrm{abc})}$ : Active filter currents

$\mathrm{I}_{\mathrm{Lf}(\mathrm{abc})}$ : Fundamental components of the load line currents

$\mathrm{I}_{\mathrm{L}(\mathrm{abc})}$ : Load line currents

$\mathrm{I}_{\mathrm{h}(\mathrm{abc})}$ : Harmonics currents

Appling Kirchhoff's current law at PCC, yields: 


$$
\begin{aligned}
& I_{s a}=I_{L a}+I_{h a}=I_{L a}+I_{L f a}-I_{L a}=I_{L f a} \\
& I_{s b}=I_{L b}+I_{h b}=I_{L b}+I_{L f b}-I_{L b}=I_{L f b} \\
& I_{s c}=I_{L c}+I_{h c}=I_{L c}+I_{L f c}-I_{L c}=I_{L f c}
\end{aligned}
$$

The current drawn out from the PCC is harmonic free as can be seen from (4) to (6).

\section{DISCRETE FOURIER TRANSFORM (DFT)}

The detailed block diagram of a DFT is shown in Figure 3. It performs a Fourier analysis on the current signal and obtains the fundamental harmonic component in terms of their peak magnitude and phase over a running window of one cycle. The Clock block output represents the current simulation time at each simulation step. The real and imaginary components of the signal have been calculated using DFT as [21].

$$
\begin{aligned}
& \mathrm{V}_{\mathrm{P}} \cos \theta=\frac{2}{\mathrm{~N}} \sum_{\mathrm{k}=0}^{\mathrm{N}-1} \mathrm{v}_{\mathrm{k}} \sin \mathrm{k} \omega \Delta \mathrm{t} \\
& \mathrm{V}_{\mathrm{P}} \sin \theta=\frac{2}{\mathrm{~N}} \sum_{\mathrm{k}=0}^{\mathrm{N}-1} \mathrm{~V}_{\mathrm{k}} \cos \mathrm{k} \omega \Delta \mathrm{t}
\end{aligned}
$$

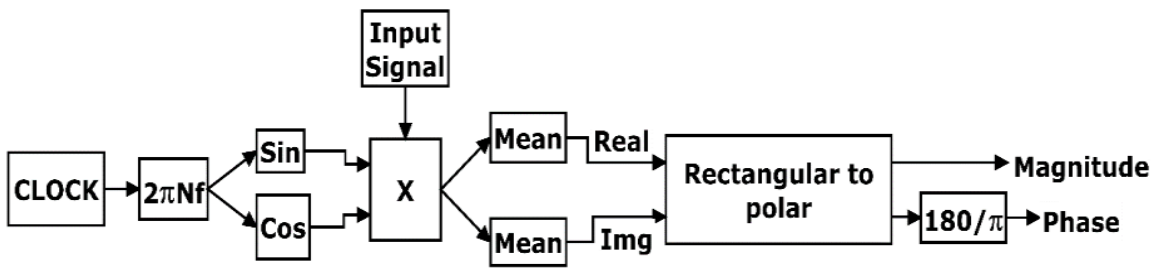

Figure 3. DFT block diagram

Where $V_{p}$ and $\theta$ represent the peak and phase angle of the fundamental component respectively, $N$ is the number of samples per one cycle of the fundamental frequency and $\Delta t$ is the sampling time interval. If a signal with $100 \mathrm{~A}$ peak fundamental and distorted with $5^{\text {th }}$ harmonic current with $20 \mathrm{~A}$ peak is introduced to a DFT algorithm at a sampling rate of 1000 sample per cycle for 5 cycles, the response of the DFT algorithm result is shown in Figure 4. Here, the signal magnitude is assumed zero for the first cycle. It can be seen that the algorithm needs one full cycle to obtain the peak value. The sin and cos factors/coefficients are shown in Figure 5. The main advantage of this algorithm is that it can attenuates all harmonics and noise effectively as can be observed from the frequency response of the DFT shown in Figure 6.
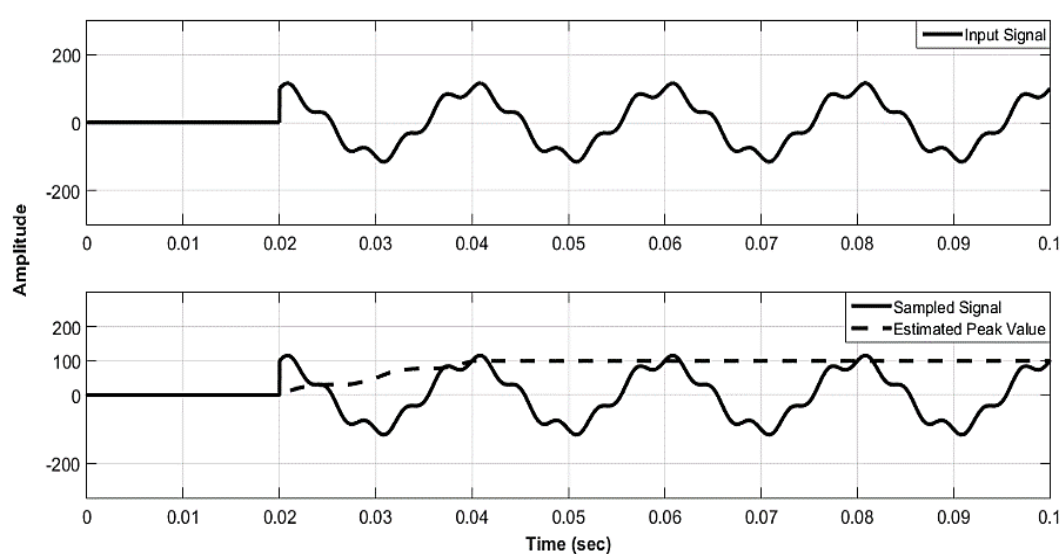

Figure 4. Input signal, sampled signal and the estimated peak value 


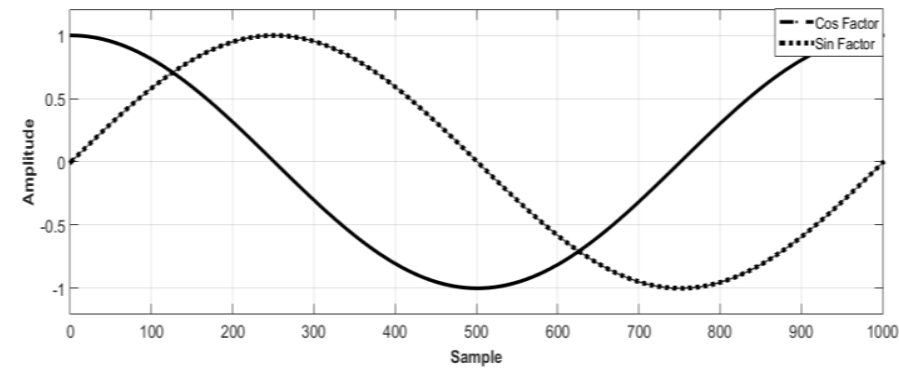

Figure 5. Sin and Cos factors

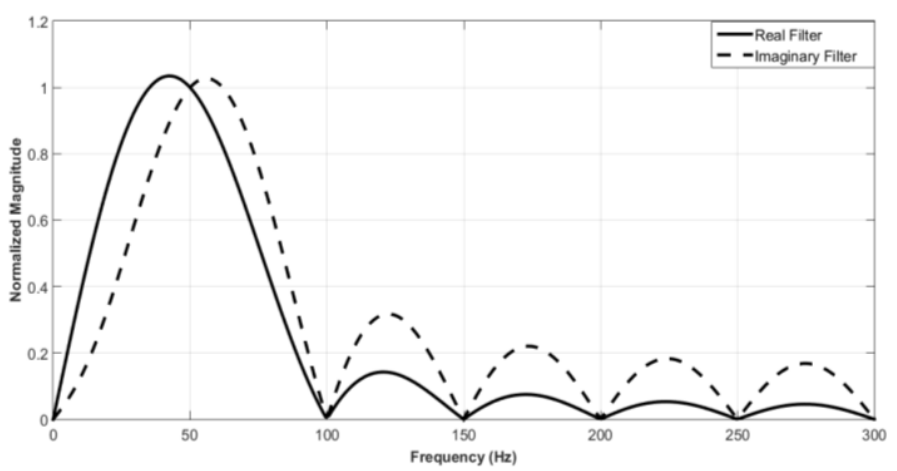

Figure 6. Real and imaginary filter frequency response

\section{SAPF TEST MODEL SIMULATION}

\subsection{SAPF test model}

The test model of the SAPF is shown in Figure 7, which consists of two rectifiers with 5000A DC load connected to each rectifier. The SAPF consists of three-phase inverter, line inductance and circuit breaker. The control block subsystem is shown in Figure 8. The fundamental current signal is extracted by using the DFT algorithm and then converted from frequency domain to time domain. The Simulink model for extraction the fundamental current signal is shown in Figure 9. The reference current $\left(\mathrm{I}_{\mathrm{h}}\right)$ signal are obtained by subtracting the load current signals from fundamental current signals. The reference current is then fed into a gate control block that will generate the required gate pulses for the three-phase inverter. The gate control block contains hysteresis controllers that generate pulses to force inverter output to follow the harmonics generated by the load. The gate control philosophy is discussed in detail in [11].

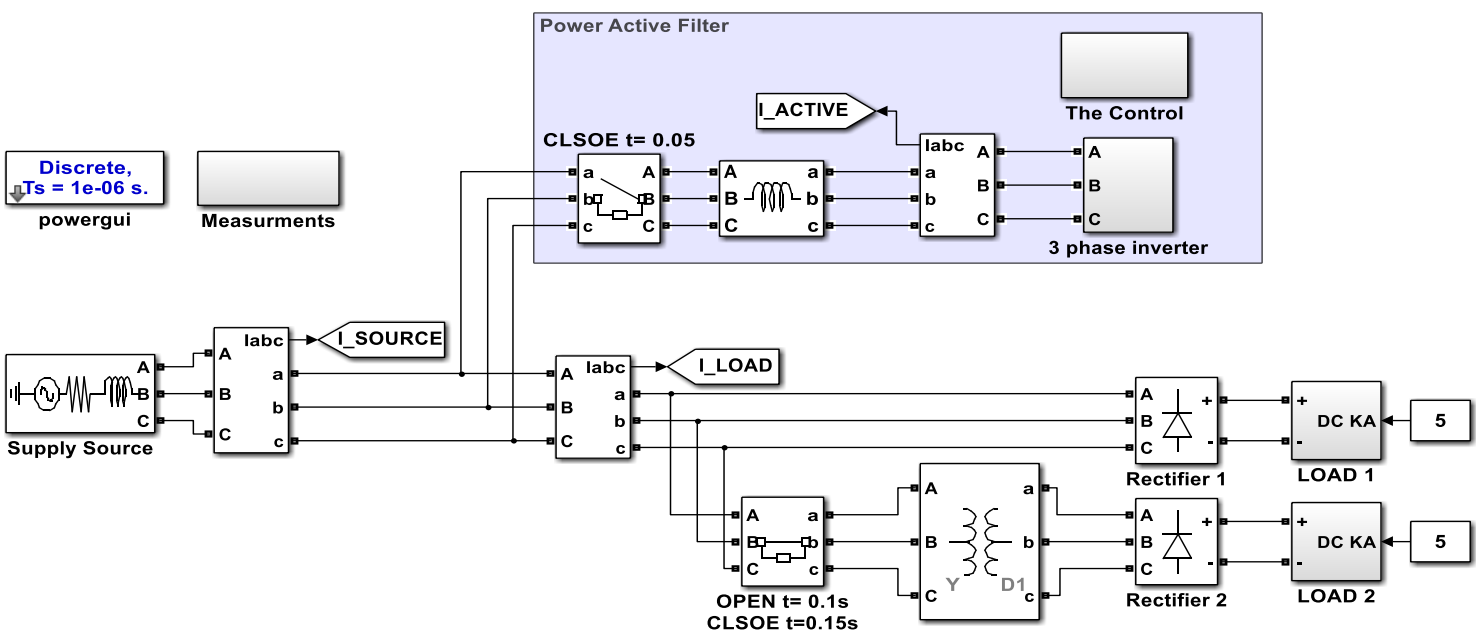

Figure 7. Simulink Test model of the SAPF 


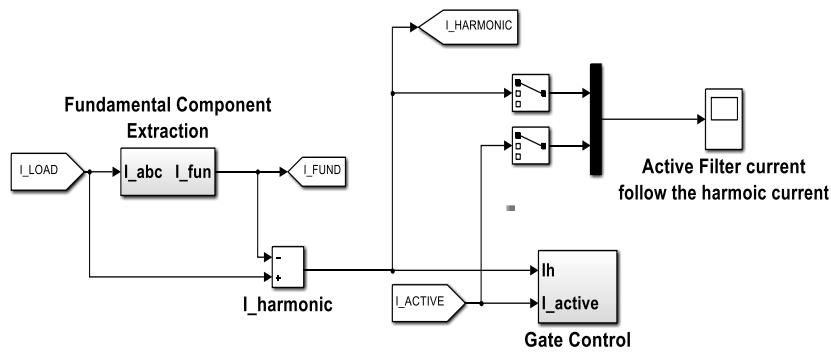

Figure 8. Inside the control block

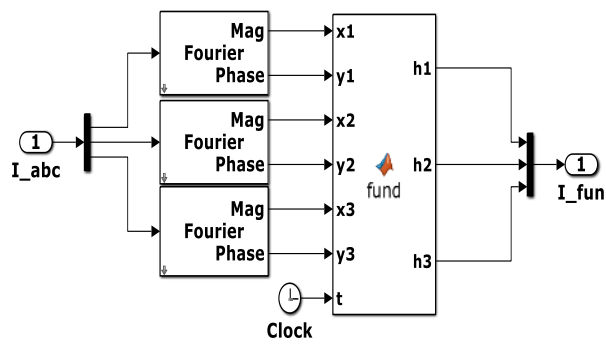

Figure 9. Fundamental signal extraction and time domain conversion

\subsection{SAPF test model simulation results and performance}

The SAPF test model shown in Figure 7 is simulated and its performance is shown in Figure 10 for different operating conditions. At $\mathrm{t}=0 \mathrm{sec}$, rectifier 1 and 2 are in service and operating in parallel to create 12 pulse output system with TDD equal to $3.4 \%$. At $\mathrm{t}=0.05 \mathrm{sec}$, the active filter is connected to the system and consequently the TDD reduced to $0.24 \%$. To examine the response of the SAPF, rectifier 2 is taken out of service at $\mathrm{t}=0.1 \mathrm{sec}$ creating a 6 -pulse output system and returned back in service at $\mathrm{t}=0.15 \mathrm{sec}$. It can be seen from Figure 10 that the system responded adaptively to this change and maintain the source TDD below $0.3 \%$.

As the system load changed from 12-pulse to 6-pulses by disconnecting rectifier 2, the SAPF changes its response in order to maintain the input current at very low TDD. It can also be seen from Figure 11 that the SAPF current $\left(\mathrm{I}_{\mathrm{A}}\right)$ adapts to the change in the system load. At $\mathrm{t}=0.1 \mathrm{sec}$, the load current reduced and system configuration changed from 12-pulse to 6-pulse. The SAPF has reacted to this change and adjusted the compensation current $\left(\mathrm{I}_{\mathrm{A}}\right)$ in order to maintain the input current sinusoidal.
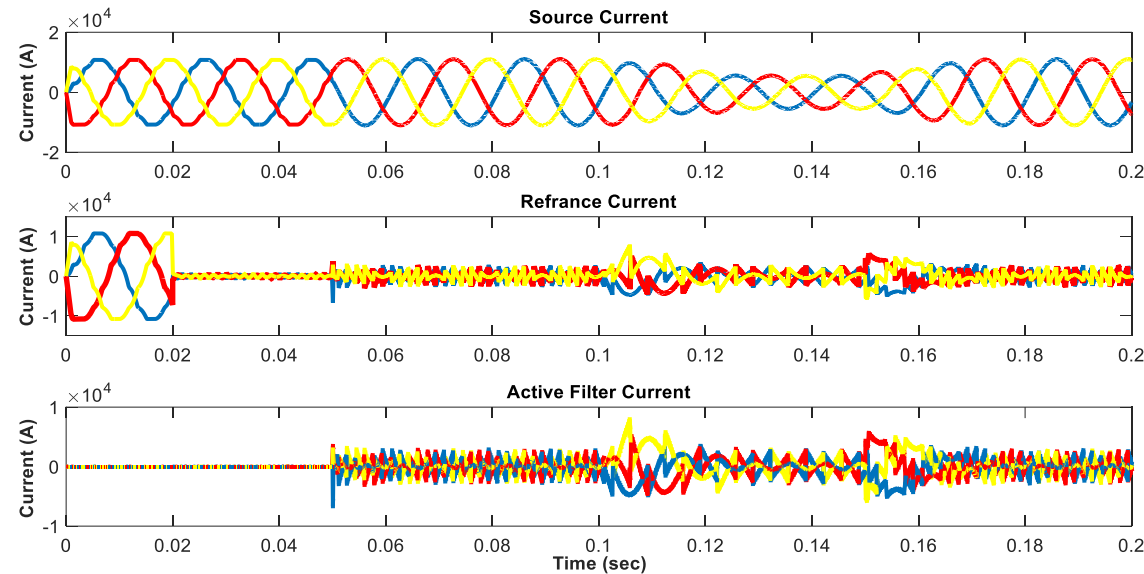

Figure 10. Performance of the SAPF results

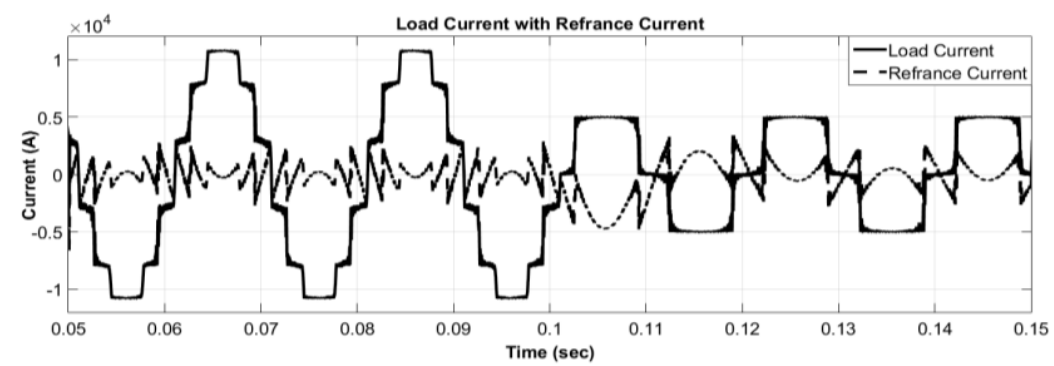

Figure 11. Performance of the SAPF results 


\section{ALUMINUM POTLINE SCHEME WITH SAPF SIMULATION AND RESULTS}

With same pot line Rectiformers system of ALBA PL6, the SAPF is connected to the primary side of the regulating transformer as shown in Figure 12 in order to ensure that the current flowing into the regulating transformer is harmonics free and to minimize the harmonic distortion at the PCC. The SAPF scheme is simulated using the MATLAB/SIMULINK. The electrical parameters of the simulated system are provided in Table 1, which is obtained from the actual proposed data for ALBA PL6 units. The phase shift between the units is determined as [22]:

$$
\text { Phase shift }=\frac{60}{\text { Number of converters }}=5^{\circ}
$$

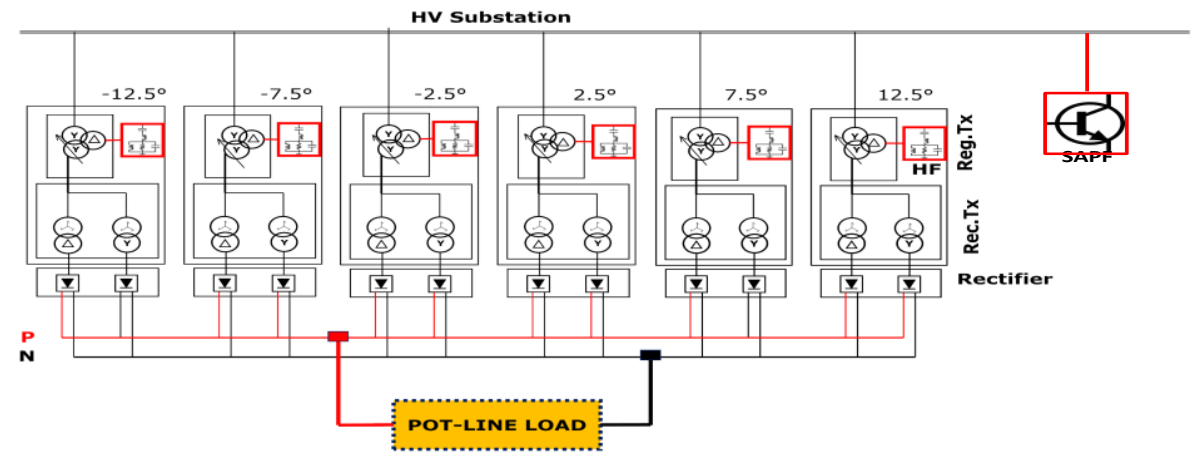

Figure 12. Pot line Rectiformer scheme with SAPF

Table 1. Electrical parameter of the system

\begin{tabular}{|c|c|c|c|c|}
\hline \multicolumn{5}{|c|}{ Main Supply Source } \\
\hline $\mathrm{KV}=220$ & & $\begin{array}{l}\mathrm{Hz}=50 \\
\text { Under Ground Cable }\end{array}$ & MVAsc $=8000$ & $\mathrm{X} / \mathrm{R}=24$ \\
\hline $\mathrm{R}=40 \mu \Omega / \mathrm{m}$ & & $\begin{aligned} \mathrm{L}= & 636 \mu \mathrm{H} / \mathrm{m} \\
& \text { Regulating Transformer }\end{aligned}$ & $\mathrm{C}=0.21 \mu \mathrm{F} / \mathrm{m}$ & $\mathrm{L}=100 \mathrm{~m}$ \\
\hline YY $\Delta$ & $\mathrm{MVA}=230$ & KVs $=95$ & $\mathrm{KVp}=220$ & $\mathrm{KVt}=28$ \\
\hline $\mathrm{Lp}=47.5 \mathrm{mH}$ & & $\mathrm{s}=10.5 \mathrm{mH}$ & $\mathrm{Lt}=0.56 \mu \mathrm{H}$ & \\
\hline $\mathrm{ZY} \Delta$ & $\begin{array}{l}\text { MVA= } \\
2 \times 115\end{array}$ & $\begin{array}{l}\text { Rectifier Transformer } \\
\qquad K V p=95\end{array}$ & $\mathrm{KVs}=1.3$ & \\
\hline MVar $=40$ & & $\begin{array}{c}\text { PHF } \\
\text { Tuning } \mathrm{Hz}=5^{\text {th }} \& 11^{\text {th }} \\
\end{array}$ & $\mathrm{Q}=5$ & $\mathrm{KV}=28$ \\
\hline
\end{tabular}

The PHF is tuned at the $5^{\text {th }}$ and $11^{\text {th }}$ harmonic frequencies as indicated in Table $\mathrm{I}$. The $11^{\text {th }}$ tuning frequency is selected in order to eliminate the characteristic harmonic of the 12-pulse rectifier, whereas the $5^{\text {th }}$ tuning frequency is selected in order to target the low order uncharacteristic harmonics, which as a result of practical reasons such as unbalance between the two rectifier outputs and unequal short circuit impedance of each Rectiformer.

ALBA designed their new pot line 6 (PL6) to supply the required DC power at N-2, whereas $\mathrm{N}$ is the number of Rectiformer units in service. Hence, the performance of the proposed scheme, the conventional scheme and ALBA PL6 scheme are compared and evaluated at three practical operating conditions. The operating conditions are as:

- N-Condition: represents the normal operating condition of the potline in which all the Recteformer units are in service.

- N-1 Condition: represents the operating condition in which one Rectiformer unit is taken out of service.

- N-2 Condition: represents the operating conditions in which two Recteformer units are taken out of service.

For each of the above three operating conditions, the three schemes are tested when all the filters are in service and when one block of the filter units are taken out of service. The results for $\mathrm{N}$ operating condition are shown in Figure 13 (a). When the potline is running under normal operating condition which represent $80 \%$ of the year, the SAPF scheme shows lower harmonic distortion as compared to the conventional and PL6 schemes even when the SAPF taken out of service. When SAPF taken out of service, the PHF connected to the tertiary windings will maintain the harmonic distortion at a very low level. 
However, when the tertiary winding PHF is taken out of service in SPAF scheme, the harmonics at PCC will also remain very low because of SAPF presence at PCC. When the tertiary winding PHF is taken out of service in SAPF scheme, the behavior is almost similar to PL6 scheme as both are with the same configuration. In all the operating conditions, when the SAPF is in service or out of service, the SAPF scheme is showing superior capability in attenuating the harmonics at PCC and at unit terminal as compared to the conventional and the PL6 schemes as shown in Figures 13 (a), (b) and (c). When the SAPF is in or out of service in all the operating conditions, the harmonics at PCC satisfied the IEEE 519 recommended values. When the PHF is out of service in the SAPF scheme, the THD exceeded the limit by $8 \%$ when the Rectiformer unit is in out of service condition (N-1).

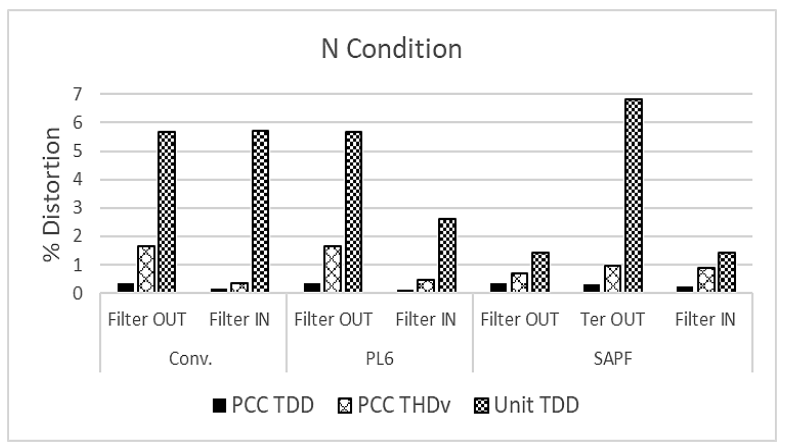

(a)

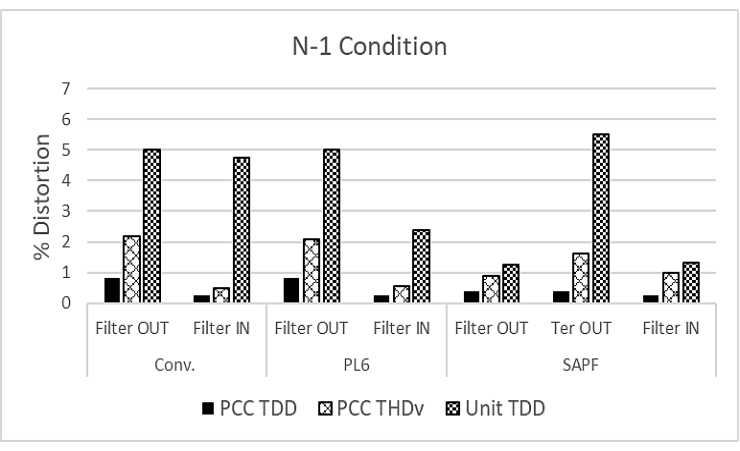

(b)

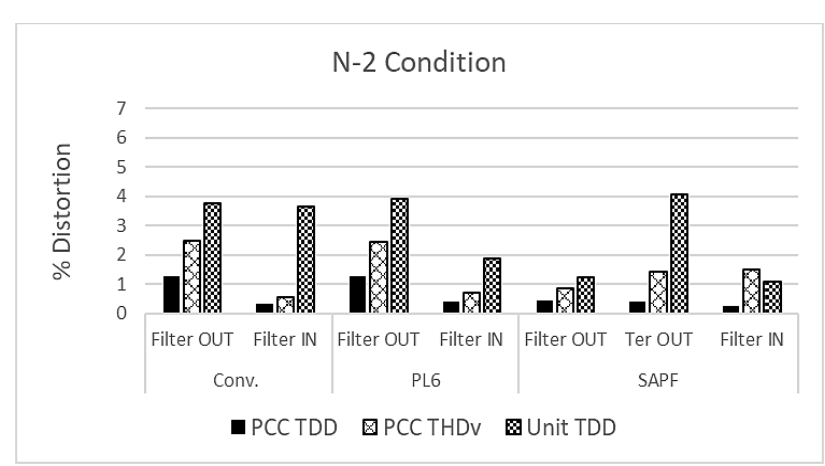

(c)

Figure 13. Simulation results summary for the performance of the proposed scheme (SAPF), the conventional scheme (Conv) and ALBA PL6 scheme (PL6) under different operating conditions: (a) N-Condition,

(b) N-1 Condition and (c) N-2 Condition

\section{DISCUSSION}

Customer needs and requirements will define the potline Rectiformers scheme. Aluminum smelter with their own power generating plant may not focus on harmonics distortion levels in their network but the majority of power consumers will improve the network power factor by reactive power compensation in order to reduce the tension on the generators. Aluminum smelters that purchase the power from other suppliers are required to keep the harmonic distortion levels minimum in order not to affect other consumers and to avoid extra charges from the power supplier. The use of capacitor banks alone for reactive power compensation is possible but with the risk of harmonics amplification. That is why capacitor banks are installed with tuned passive harmonic filters which may expose the network to a possible risk of resonance condition. The work presented in [23]-[25] discussed the future scheme of aluminum smelter pot line Rectiformers.

The future type of the rectifier used in electrolysis process will be active rectifier type whereas high frequency switching devices will replace the diodes or the thyristors in order to improve the power quality. However, this technology is not available for high current application like Rectiformers due to unavailability of the suitable cost-effective power electronic devices. The same concept can be applied to the passive harmonic filters used in aluminum smelter. Active harmonic filter can be considered as the future to replace the passive harmonic filter in aluminum smelters. As it can be seen from the results in Figure 13, the 
SAPF scheme has the superior capability of attenuating the harmonics compared to all other schemes discussed in this thesis at normal operating condition.

\section{CONCLUSION}

The SAPF used here is without reactive power compensation elements. So, for the reactive power compensation, another PHF connected to the tertiary winding was used. The SAPF discussed shows good results from the harmonic distortion reduction point of view and it is also suitable for potline load behavior. The SAPF is a good solution as it is self-adaptive and does not involve any risk of resonant with the power network impedance as the SAPF represent a current source independent from the power network impedance. SAPF is not expected to replace the passive filter at this time as it is not economical solution to be used in aluminum smelter power network. However, hybrid solution can be conceived. The SAPF provides an advanced step and proactive action in order to revamp the harmonic distortion equipment in aluminum smelter power network.

\section{ACKNOWLEDGEMENTS}

The authors would like to thank Aluminum Bahrain (ALBA) for their support in this research work and for providing the required actual system data.

\section{REFERENCES}

[1] "IEEE Recommended Practice and Requirements for Harmonic Control in Electric Power Systems," IEEE Std 519, 1992, doi: 10.1109/IEEESTD.1993.114370.

[2] J. C. Das, "Modeling of system components for harmonic analysis," in Power system harmonics and passive filter designs, IEEE Press Series on Power Engineering, 2015, Chapter 12, p. 532, doi: 10.1002/9781118887059.ch12.

[3] H. K. Thakkar, P. K. Soori, and S. Chacko, "Harmonics in industrial power networks of aluminium smelters - A comprehensive mitigation approach," International Journal of Smart Grid and Clean Energy, vol. 4, no. 1, pp. 77-84, 2015, doi: 10.12720/sgce.4.1.77-84.

[4] F. Peng and J. Lai, "Application considerations and compensation characteristics of shunt active and series active filters in power systems," Conference: 7, International Conference on Harmonic and Quality of Power, 1996, United States.

[5] L. Gyugyi and E.C. Strycula, “Active AC Power Filters,” in Proc. IEEE/IAS Annual Meeting Record, 1976, pp. 529-535.

[6] H. Akagi, Y. Kanazawa, and A. Nabae, "Instantaneous Reactive Power Compensators Comprising Switching Devices without Energy Storage Components," IEEE Trans. on IAS, vol. IA-20, no. 3, pp. 625-630, 1984, doi: 10.1109/tia.1984.4504460.

[7] M. Lada, I. Bugis, and Md H. Talib, "Simulation of shunt active power filter using MATLAB/Simulink," $4^{\text {th }}$ International Power Engineering and Optimization Conference (PEOCO), 2010, pp. 371-375, doi: 10.1109/PEOCO.2010.5559218.

[8] A. K. Al-Othman, M. E. Al Sharidah, N. A. Ahmed, and B. N. Alajmi, "Model Predictive Control for Shunt Active Power Filter in Synchronous Reference Frame," Journal of Electrical Engineering and Technology, vo. 11, no. 2, pp. 405-415, 2016, doi: 10.5370/JEET.2016.11.2.405.

[9] D. Schwanz, A. Bagheri, M. Bollen, and A. Larsson, "Active Harmonic Filters: control techniques review," 17 ${ }^{\text {th }}$ International Conference on Harmonics and Quality of Power (ICHQP), 2016, pp. 36-41, doi: 10.1109/ICHQP.2016.7783423.

[10] M. Karbasforooshan and M. Monfared, "An Adaptive Recursive Discrete Fourier Transform Technique for the Reference Current Generation of Single-Phase Shunt Active Power Filters," 7th Power Electronics, Drive Systems \& Technologies Conference (PEDSTC 2016), 2016, pp. 253-259, doi: 10.1109/PEDSTC.2016.7556870.

[11] M. Taleb, "Interconnection of a wind driven induction machine with the power utilities: a simulation study," International Journal of Renewable Energy Technology (IJRET), vol. 7, no. 2, pp. 113-124, 2016, doi: 10.1504/ijret.2016.076087.

[12] M. R. Iravani et al., "A benchmark system for digital time-domain simulation of an active power filter," IEEE transactions on power delivery, vol. 20, no.1, pp. 234-241, 2005, doi: 10.1109/TPWRD.2004.837815.

[13] S. Perera, V. J. Gosbell, D. Mannix, and N. Gersch, "Investigation into the harmonic behaviour of multipulse converter systems in an aluminium smelter," University of Wollongong, Boyne Smelters Limited, Queensland. Power quality center, 2000. Available: www.elec.uow.edu.au/apqrc/content/papers/AUPEC/AUPEC00_2.pdf.

[14] P. Pollock and C. Duffey, "Power quality and corrective action in an aluminum smelter," Petroleum and Chemical Industry conference Industry Applications Society 45th Annual, 1998, pp. 181-189, doi: 10.1109/PCICON.1998.727958.

[15] S.V. Kulkarni and S. A. Khaparde, Transformer Engineering Design and Practice, Marcel Dekker Inc, NY, USA, 2004, ch. 25.

[16] A. T. Yokoyama et al., "Investigation and mitigation of the amplification of the harmonic current to filtering system of an aluminum smelter," Proceedings of the $6^{\text {th }}$ WSEAS International Conference on Power Systems, Lisbon, Portugal, Sep. 2006, pp. 183-188.

[17] M. Wiestner, "Power quality results in energy efficient aluminium smelter," ABB Switzerland, ABB Technical publication, 2010.

[18] Z. Zhao, L. Luo, J. Xu, T. Tran, and Z. Zhang "Operational characteristics of a filtering rectifier transformer for industrial power systems," Turkish Journal of Electrical Engineering \& Computer Sciences, vol. 21, no. 5, pp. 1272-1283, 2013, doi:10.3906/elk$1112-53$.

[19] A. Collier, G. Greve, and S. Veldurthi, "Workhorses of industry - Industrial transformers in a DC environment," ABB Technical publication, ABB review special report, Doc: 9AKK105713A2323, Nov. 2012.

[20] M. Al-Mahari, S. A. Al-Mawsawi, and F. Albasri, "A New Aluminum Pot Line Rectiformer Scheme with Effective Harmonic Suppression Capability," International Journal of Power Electronics and Drive System (IJPEDS), vol. 9, no. 4, pp. 1573-1583, 2018, doi: 10.11591/ijpeds.v9.i4.pp1573-1583.

[21] A. Phadke and J. Thorp, Computer Relaying for Power Systems, John Wiley \& Sons Ltd, USA, 2009, ch. 5, pp. 149.

[22] M. P. Kazmierkowski, R. Krishana, and F. Blaabjerg, Control in Power Electronics, $1^{\text {st }}$ Ed., Elsevier Inc, USA, 2002, doi: 10.1016/B978-0-12-402772-5.X5000-5. 
[23] T. Siebert, A. Troedson, and S. Ebner, "AC to DC Power Conversion Now and in the Future," IEEE transactions on industry applications, vol. 38, no.4, pp. 145-152, 2002, doi: 10.1109/TIA.2002.800570.

[24] M. Ayoub and F. Robinson, "A comparative study between diode and thyristor-based AC to DC converters for aluminium smelting process," 7th IEEE GCC Conference and Exhibition (GCC 2013), Doha, Qatar, 2013, pp. 622-627, doi: 10.1109/IEEEGCC.2013.6705851.

[25] J. R. Rodriguez and J. Pontt, "Large current rectifiers: State of the art and future trends," IEEE Transactions on Industrial Electronics, vol. 52, no. 3, pp. 738-746, 2005, doi: 10.1109/TIE.2005.843949.

\section{BIOGRAPHIES OF AUTHORS}
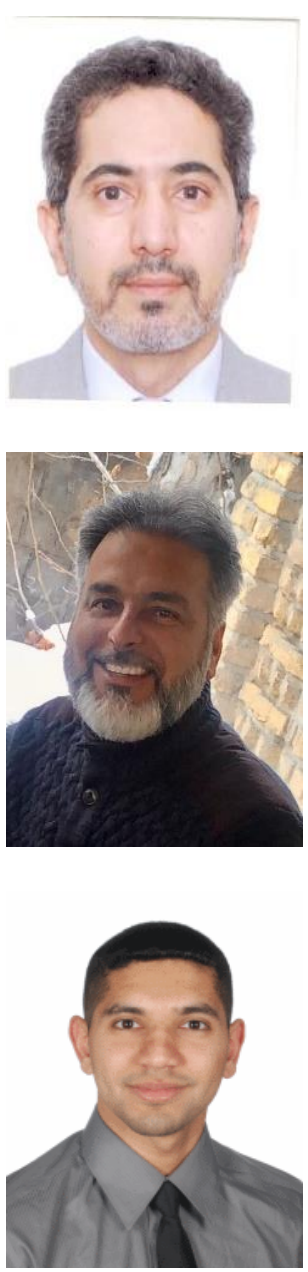

Fadhel Abbas Albasri (iD 8 sc P received the B.Sc. and M.Sc. degrees in Electrical Engineering from University of Bahrain, Bahrain, and Ph.D. degree in the same field from University of Western Ontario, Canada, in 1992, 1997 and 2007, respectively. He worked in Ministry of Electricity and Water, Bahrain, as an electrical engineer from 1993 to 1994. In 1994, he joined the University of Bahrain as teaching and research assistant and currently an assistant professor in the department of electrical engineering. His research interest is power systems protection, power systems analysis and FACTS-device. He can be contacted at email: falbasri@uob.edu.bh.

Sayed Ali Al-Mawsawi (D) ST SC received his B.Sc. degree (F. Hons) in Electrical and Electronics Engineering from University of Bahrain in 1988. He received the M.Sc. degree in Power Electronics from University of Bradford in 1990 and Ph.D. degree in Power Electronics from Imperial College, University of London, UK, in 1995. Currently he is an associate professor with the University of Bahrain. Dr. Al-Mawsawi published number of papers in a highly reputed refereed international journals and conferences on Power Electronics Applications and FACTS devices. His research interest includes Power Electronics, FACTS Devices and Control Applications. He can be contacted at email: aalmossawi@uob.edu.bh.

Mahmood Al-Mahari (D) SC S received his B.Sc. and M.Sc. degrees in Electrical Engineering from the University of Bahrain in 2010 and 2018, respectively. Currently, he is with Aluminum Bahrain power department working as maintenance electrical engineer responsible for Potlines Rectiformer maintenance, associated services and system reliability and availability. He can be contacted at email: m.almahari@gmail.com. 